\title{
Description of two new filtering carnivore Drusus species (Limnephilidae, Drusinae) from the Western Balkans
}

\author{
Simon Vitecek', Mladen Kučinić ${ }^{2}$ János Oláh ${ }^{3}$, Ana Previšić ${ }^{2}$, Miklós Bálint ${ }^{4}$, \\ Lujza Keresztes ${ }^{5}$, Johann Waringer', Steffen U. Pauls ${ }^{4}$, Wolfram Graf ${ }^{6}$
}

I Department of Limnology and Bio-Oceanography, University of Vienna, Althanstrasse 14, A-1090 Vienna, Austria 2 Department of Biology, Faculty of Science, University of Zagreb, Rooseveltov trg 6, HR-10000 Zagreb, Croatia 3 Tarján u. 28, H-4032 Debrecen, Hungary 4 Senckenberg Biodiversity and Climate Research Centre (BiK-F), Senckenberganlage 25, D-60325 Frankfurt a.M., Germany 5 Hungarian Department of Biology and Ecology, Babeş-Bolyai University, Clinicilor 5-7, 400006 Cluj-Napoca, Romania 6 Institute of Hydrobiology and Aquatic Ecology Management, University of Natural Resources, Max-Emanuelstrasse 17, A-1180 Vienna, Austria

Corresponding author: Simon Vitecek (simon.vitecek@univie.ac.at)

Academic editor: R. Holzenthal | Received 28 April 2015 | Accepted 26 June 2015 | Published 16 July 2015

http://zoobank.org/2E222ADB-E6DE-415A-955E-4EBFF59E67A1

Citation: Vitecek S, Kučinić M, Oláh J, Previšić A, Bálint M, Keresztes L, Waringer J, Pauls SU, Graf W (2015) Description of two new filtering carnivore Drusus species (Limnephilidae, Drusinae) from the Western Balkans. ZooKeys 513: 79-104. doi: 10.3897/zookeys.513.9908

Dedicated to Hans Malicky on the occasion of his 80th birthday

\begin{abstract}
Two new species of the genus Drusus (Trichoptera, Limnephilidae, Drusinae) from the Western Balkans are described. Additionally, observations on the biodiversity and threats to the region's endemic aquatic fauna are discussed. Drusus krpachi sp. n. is a micro-endemic of the Korab Mountains, Macedonia, and D. malickyi sp. n. is a micro-endemic of the Prokletije Mountains, Albania. Both new species are most similar to $D$. macedonicus but differ from the latter in the shape of segment IX, the shape of the tips of the intermediate appendages in lateral view, the shape of the inferior appendages, and the form and shape of the parameres. In addition, males of the European species of filtering carnivore Drusinae are diagnosed and illustrated, including Cryptothrix nebulicola McLachlan, Drusus chrysotus Rambur, D. discolor Rambur, D. macedonicus Schmid, D. meridionalis Kumanski, D. muelleri McLachlan, D. romanicus Murgoci and Botosaneanu, and D. siveci Malicky. These additions to the Western Balkan fauna demonstrate the significance of this region for European biodiversity and further highlight the importance of faunistic studies in Europe.
\end{abstract}

Copyright Simon Vitecek et al. This is an open access article distributed under the terms of the Creative Commons Attribution License (CC BY 4.0), which permits unrestricted use, distribution, and reproduction in any medium, provided the original author and source are credited. 


\section{Keywords}

Caddisfly, aquatic diversity, Mediterranean, taxonomy, conservation, Southern Europe

\section{Introduction}

The Western Balkans harbour high biodiversity including high numbers of endemic species. This has been attributed to historic climate conditions and the highly diverse geology of the region (e.g., Neubauer 2002, Reed et al. 2004, Chiari et al 2011) that permitted perseverance of taxa in glacial refugia (e.g., Tzedakis 2004, 2009; Médail and Diadema 2009), and the formation of diverse habitats. Thus, the Western Balkans are rich in endemic plant (e.g., Eastwood 2004, Petrova and Vladimirov 2010, Mered’a et al. 2011, Redžić 2011), vertebrate and invertebrate species (e.g., Bianco 1998, Bănărescu 2004, Kryštufek 2004, Griffiths and Frogley 2004, Bohlen et al. 2006, Guéorguiev 2007, Deltshev 2008, Pešić and Glöer 2013). The Western Balkans also have been identified as a hotspot of aquatic biodiversity, with high endemism and cryptic diversity (Bănărescu 2004, Previšić et al. 2014a). Climate change and its detrimental effects on biodiversity (e.g., Hering et al. 2009, Bálint et al. 2011) have focused attention on freshwater biota throughout Europe, including the Western Balkans (e.g., Zakšek et al. 2009, Klobučar et al. 2013, Weiss et al. 2014).

Faunal studies on Western Balkan aquatic biodiversity recovered intriguing biogeographic patterns and several new species (e.g., Petkovski et al. 2009, Pešić and Glöer 2013, Vitecek et al. 2015). Research on the caddisfly fauna of the Western Balkans further suggests several factors, such as karstification, as drivers of speciation (Previšić et al. 2009, 2014b). The limnephilid subfamily Drusinae is particularly species-rich in the Western Balkans, including a high proportion of micro-endemics sensu Graf et al. (2008), i.e., taxa restricted to small geographic units within an ecoregion sensu Illies (1978) (Malicky 2004; Graf et al. 2008; Oláh 2010, 2011; Kučinić et al. 2011a,b; Oláh and Kovács 2013; Previšić et al. 2014a, b; Vitecek et al. 2015; Ibrahimi et al. pers. comm.).

The subfamily Drusinae Banks comprises roughly 110 species in 8 genera (Malicky 2004, 2005; Oláh 2010, 2011; Oláh and Kovács 2013; Previšić et al. 2014a; Vitecek et al. 2015; Ibrahimi et al. pers. comm.). Ecologically, most species are crenobiont (Graf et al. 2008), and as larvae fall into one of three different feeding groups: filtering carnivores, omnivorous shredders and scraping grazers (Pauls et al. 2008, Graf et al. 2009). The adults of each larval feeding group are also characterized by a set of synapomorphies (Vitecek et al. in press). Filtering carnivorous Drusinae males uniquely exhibit laterally positioned gland openings at the fifth abdominal sternite and parallel wing veins in the hind wing anal field (depicted in Vitecek et al. in press). The largest genus Drusus is paraphyletic (Pauls et al. 2008) and comprises 86 species of all feeding types (Malicky 2004, 2005; Graf et al. 2008; Kučinić et al. 2011a; Oláh 2010, 2011; Oláh and Kovács 2013; Vitecek et al. 2015; Vitecek et al. in press; Ibrahimi et al. pers. comm.). The monotypic genus Cryptothrix (C. nebulicola McLachlan) is also a filtering carnivore (Bohle 1987, Graf et al. 2008), and thus represents another filtering carnivorous Drusinae sensu Pauls et al. 2008, the systematic position of which is discussed in Vitecek et al. (in press). 
Here we describe two new filtering carnivore Drusus species. Additionally, we provide re-descriptions of filtering carnivorous Drusinae sensu Pauls et al. (2008) in order to facilitate identification of known filtering carnivorous Drusinae, and identification of new species.

\section{Materials and methods}

Adults were collected using sweep nets and by handpicking. Collected specimens were stored in $96 \% \mathrm{EthOH}$. Male and female genitalia were examined after being cleared in either $\mathrm{KOH}$ or lactic acid. Nomenclature of male genitalia of Drusus follows Nielsen (1957, for Limnephilus flavicornis Fabricius) using the simplifying terms "superior appendages" for the lateral processes of segment X (cerci sensu Snodgrass 1935), and "intermediate appendages" for the sclerite and the anterior process of segment X (paraproct sensu Snodgrass 1935). Nomenclature of larval morphological features follows Wiggins (1998) and Waringer and Graf (2011), nomenclature of primary setae and setal areas follows Wiggins (1998). Illustrations were prepared according to Thomson and Holzenthal (2010) in which pencil drawings made with a camera lucida are digitized, edited and digitally inked in Adobe Illustrator (v. 16.0.4, Adobe Systems Inc.).

Specimens are currently stored in the following collections: Collection Wolfram Graf (WG), Institute of Hydrobiology and Aquatic Ecology Management, University of Natural Resources, Max-Emanuelstrasse 17, A-1180 Vienna, Austria; Collection Ana Previšić (AP), Department of Biology, Faculty of Science, University of Zagreb, Rooseveltov trg 6, HR-10000 Zagreb, Croatia; Collection Mladen Kučinić (MK), Department of Biology, Faculty of Science, University of Zagreb, Rooseveltov trg 6, HR10000 Zagreb, Croatia; Collection János Oláh [János Oláh Private Collection under national protection of the Hungarian Natural History Museum, Budapest, Hungary] (JO), Tarján u. 28, H-4032 Debrecen, Hungary.

Type specimens will be deposited in museum collections upon completion of the taxonomic work.

\section{Taxonomy}

\section{Descriptions of the new species}

\section{Drusus krpachi Kučinić, Graf \& Vitecek, sp. n.} http://zoobank.org/74BBEB74-1232-4B4E-934B-D8BE6433DDCB Fig. 1

Material examined. Holotype. 1 male: Macedonia, Mavrovo National Park, Korab Mountains, česma Elem; N41.857, E 20.625; leg. Kučinić, Krpač, Mihoci; 15.VIII.2011. Currently deposited in coll. WG, will be deposited in the Croatian Natural History Museum, Zagreb, Croatia. 

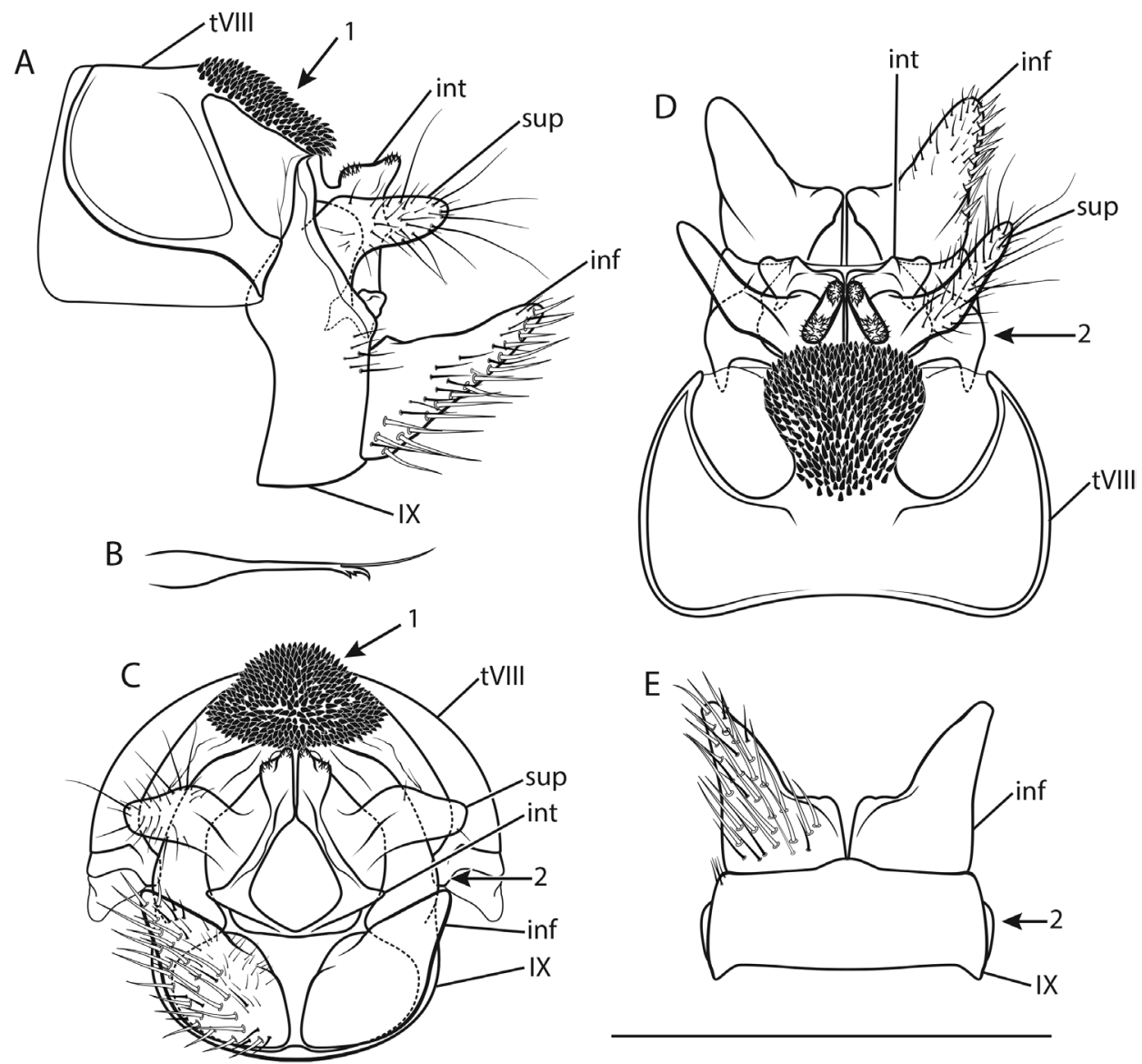

$\mathrm{E}$

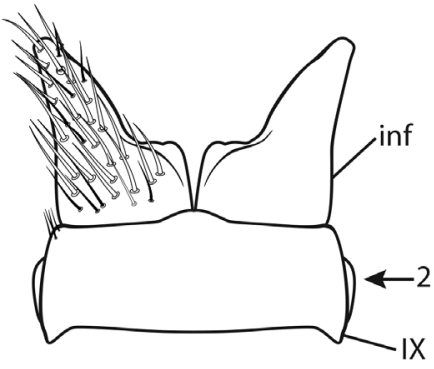

Figure I. Male genitalia of Drusus krpachi sp. n. A left lateral view B paramere, dorsal view C caudal view $\mathbf{D}$ dorsal view $\mathbf{E}$ ventral view. Abbreviations: tVIII tergite VIII, IX segment IX, sup superior appendage, int intermediate appendage, inf inferior appendage; arrow 1 indicates spinose area of tergite VIII, arrow 2 indicates lateral protrusion of segment IX. Scale bar denotes $1 \mathrm{~mm}$. Del. Vitecek.

Paratypes. 3 males: Macedonia, Mavrovo National Park, Korab Mountains, Reč; leg. Krpač, Mihoci, Kučinić; 01.VIII.2011. Currently deposited in coll. MK, two paratypes will be deposited in the Macedonian Museum of Natural History, Skopje, Republic of Macedonia, one paratype will be deposited in coll. WG.

Type locality. Macedonia, Korab Mountains.

Diagnosis. Males of the new species are most similar to D. macedonicus, but exhibit (1) a distally straight ventral half of segment IX; (2) a dorsally straight tip of the intermediate appendage distinctly separated by a proximal indentation and with small proximal and distal rough protrusions; (3) a conical inferior appendage with a proximal dorsal triangular protrusion; (4) parameres with three tines in the distal third in dorsal view. Drusus macedonicus males have a distally concave ventral half of segment IX, intermediate appendages with two rough rounded dorsad protrusions but lacking a distinct proximal indentation, distally tapering inferior appendages, and parameres with a single tine in the distal third in dorsal view. 
Description. Adults. Habitus yellow; sternites and tergites fawn; cephalic and thoracic setal areas pale; cephalic and thoracic setation blond, abdominal setation scarce, blond; legs fawn; haustellum and intersegmental integument pale, whitish; wings yellow with blond setae on veins and the membrane. Male maxillary palp 3-segmented. Forewing length $11 \mathrm{~mm}$, spur formula 1-3-3.

Male genitalia (Fig. 1). Tergite VIII (tVIII) fawn, setae absent; spinose area in lateral view approximately flat with slight dorsocaudal protrusion in cranial half, in dorsal view suboval; flanked by membranous, less sclerotized areas. Segment IX (IX) in lateral view ventrally straight distally; in caudal view dorsally approximately as wide as ventrally; with rounded lateral protrusion in the dorsal half (best seen in ventral view). Superior appendages (sup) in lateral view suboval, curved obtusely caudad in proximal third, proximally with slight dorsal protrusion, longest in anterioposterior axis: approximately 2.5 times longer than high; in dorsal view proximally slightly concave medially; medial transverse section oval. Intermediate appendages (int) in lateral view with subtriangular tip, rough areas concentrated on dorsal proximal and dorsal distal aspect; in dorsal view tips separated, oval, distally converging; in caudal view approximately triangular. Inferior appendages (inf; gonopods sensu Snodgrass 1935) in lateral view conical, proximally wide, distally slender, with proximal triangular protrusion dorsally; in ventral and dorsal view with small medial projection and slight notch. Parameres simple, in dorsal view with 3 tines in distal third: 2 mediolateral, 1 dorsal.

Female and pupa unknown. Larval description and indentification key provided by Vitecek et al. (in press).

Etymology. Named after V. Krpač, Macedonian entomologist and collector of the species.

Distribution. Micro-endemic of the Korab Mountains, Hellenic Western Balkans (ecoregion 6, Illies 1978) (Fig. 11).

\section{Drusus malickyi Oláh \& Vitecek, sp. n.} http://zoobank.org/4A7440AE-973D-4F33-858C-D53A48EEF743

Fig. 2

Material examined. Holotype. 1 male: Albania, Shkoder County, Shkoder District, Prokletije Mts, beech forest with brook above Okol; N42.42258, E19.76127; leg. Puskas 05.IX.2013. Currently deposited in coll. WG, will be deposited in János Oláh Private Collection under national protection of the Hungarian Natural History Museum, Budapest, Hungary (JO).

Type locality. Albania, Prokletije Mountains.

Diagnosis. The holotype of the new species is most similar to D. macedonicus, but exhibits (1) a sharp mediocaudal protrusion of segment IX; (2) a dorsally straight and rough tip of the intermediate appendage distinctly separated by a proximal indentation (3) a distinctly slender and constricted distal half of the inferior appendage in lateral view. Drusus macedonicus males have a mediocaudal and a ventrocaudal protrusion of segment IX, intermediate appendages with two rough rounded dorsal protrusions but lacking a distinct proximal indentation, and to a lesser degree constricted inferior appendages. 

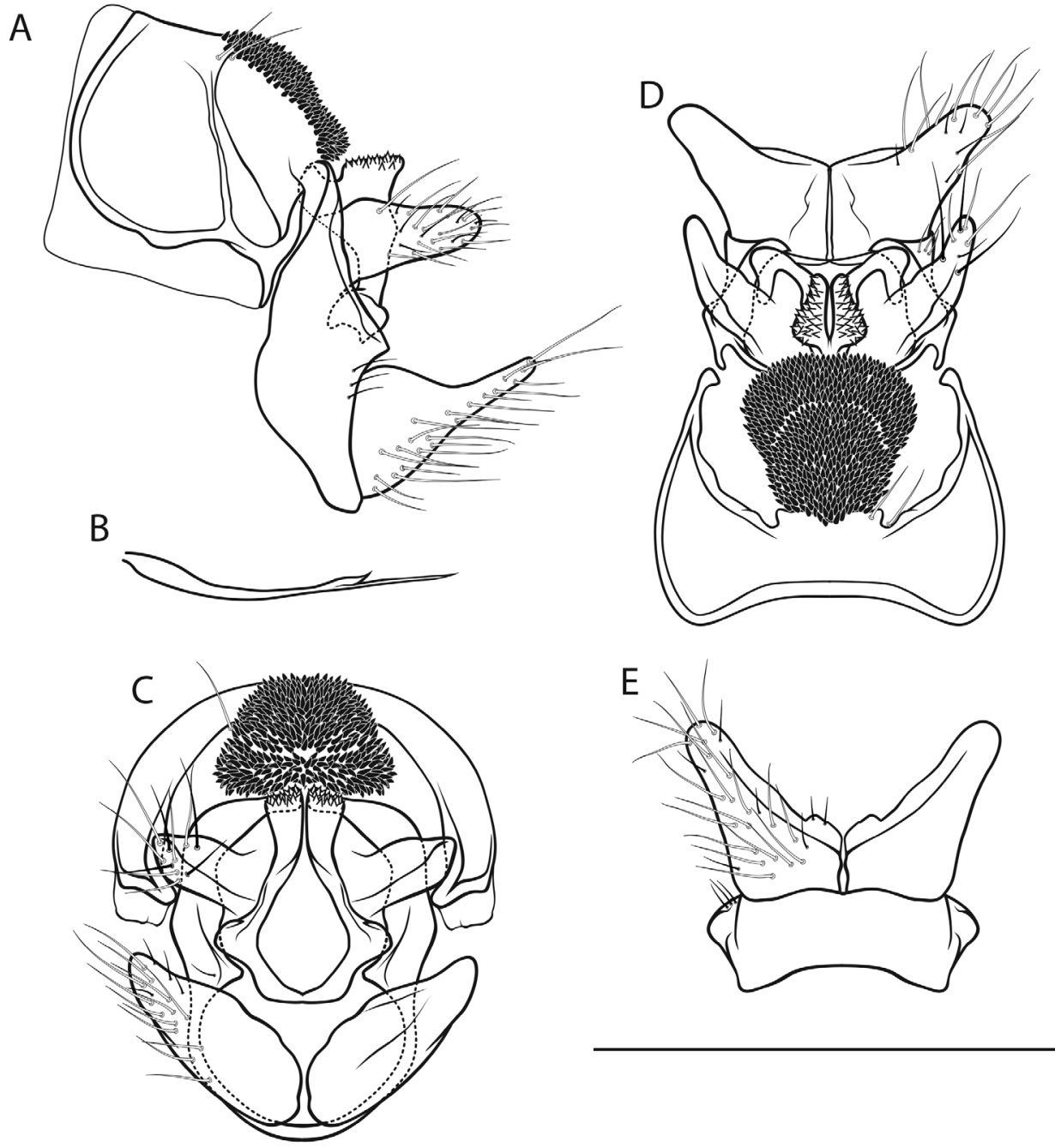

Figure 2. Male genitalia of Drusus malickyi sp. n. A left lateral view B paramere, lateral view C caudal view $\mathbf{D}$ dorsal view $\mathbf{E}$ ventral view. Scale bar denotes $1 \mathrm{~mm}$. Del. Vitecek.

Description. Adult, holotype. Habitus yellow; sternites and tergites fawn; cephalic and thoracic setal areas pale; cephalic and thoracic setation blond, abdominal setation scarce, blond; legs fawn; haustellum and intersegmental integument pale, whitish; wings yellow with blond setae on veins and the membrane. Male maxillary palp 3-segmented, forewing length $10.9 \mathrm{~mm}$, spur formula 1-3-3.

Male genitalia (Fig. 2). Tergite VIII fawn, setae scarce; spinate area in lateral view approximately flat with slight dorsad protrusion in anterior half, in dorsal view suboval; flanked by membraneous, less sclerotized areas. Segment IX in lateral view with sharp medial caudal protrusion, ventrally concave distally; in caudal view wider dorsally than ventrally; with irregular triangular, rounded lateral protrusion in dorsal half (best seen in dorsal and ventral 
views). Superior appendages in lateral view suboval, curved obtusely caudad in proximal quarter, proximally with slight dorsal and distinct ventral protrusions, longest in anterioposterior axis: approximately 2.5 times longer than high; in dorsal view proximally concave medially; medial transverse section oval. Intermediate appendages in lateral view with subtriangular, dorsally rough tip; in dorsal view tips separated, wedge-shaped, approximately parallel; in caudal view approximately triangular. Inferior appendages in lateral view subtriangular, proximally somewhat bulbous, distally slender and distinctly constricted; in ventral and dorsal views with small medial protrusion and slight notch; in ventral view with longitudinal groove delimiting medial lobe. Parameres simple, in lateral view with 1 tine in distal third.

Female, pupa and fifth instar larva unknown.

Etymology. Named after Hans Malicky, trichopterologist.

Distribution. Micro-endemic of the Prokletije Mountains, Hellenic Western Balkans (ecoregion 6) (Fig. 11).

\section{Re-descriptions of male filtering carnivore Drusinae sensu Pauls et al. (2008)}

\section{Cryptothrix nebulicola McLachlan, 1867}

Fig. 3

Material examined. 1 male: Italy, Torino, Traversella, Fondo, Burdeivier brook; leg. Vincon; 12.VII.2012. 12 males: Italy, San Marco Pass; leg. Graf; 14.VIII.2000; in coll. WG.

Type locality. Switzerland, Canton of Valais, Maienwang (Grimselpass).

Description. Adults. Habitus dark; sternites and tergites brown; cephalic and thoracic setal areas pale; cephalic, thoracic and abdominal setation blond; legs light brown to fawn, proximally darker; haustellum and intersegmental integument pale, whitish; wings dark, with dark setae. Male maxillary palp 3-segmented; forewing length 8-10 $\mathrm{mm}$; spur formula 1-2-2.

Male genitalia (Fig. 3). Tergite VIII brown, with lighter areas around alveoli; setation abundant; spinose area approximately rectangular in dorsal view; flanked by membraneous, less sclerotized areas. Segment IX in lateral view ventrally slightly concave distally; in caudal view wider dorsally than ventrally; with long, round, wedgeshaped protrusion in dorsal half (best seen in ventral view). Superior appendages in lateral view suboval, curved obtusely caudad in proximal fifth, proximally dorsal somewhat protuberant, tips slightly curved dorsad, longest in anterioposterior axis: approximately 2 times longer than high; in dorsal view medially concave, tips converging; medial transverse section lateroventrally curviconvex suboval. Intermediate appendages in lateral, dorsal and caudal views dorsally with 2 distinct tips, the proximal tip rounded, rough, the distal tip pointed, smooth; in caudal view approximately an isoceles trapezium. Inferior appendages in lateral view roughly triangular, proximally constricted, ventrocaudally slightly concave; in dorsal and ventral views tips converging; in ventral view with longitudinal groove delimiting medial lobe. Parameres simple, rodlike, medially and distally somewhat bulbous. 

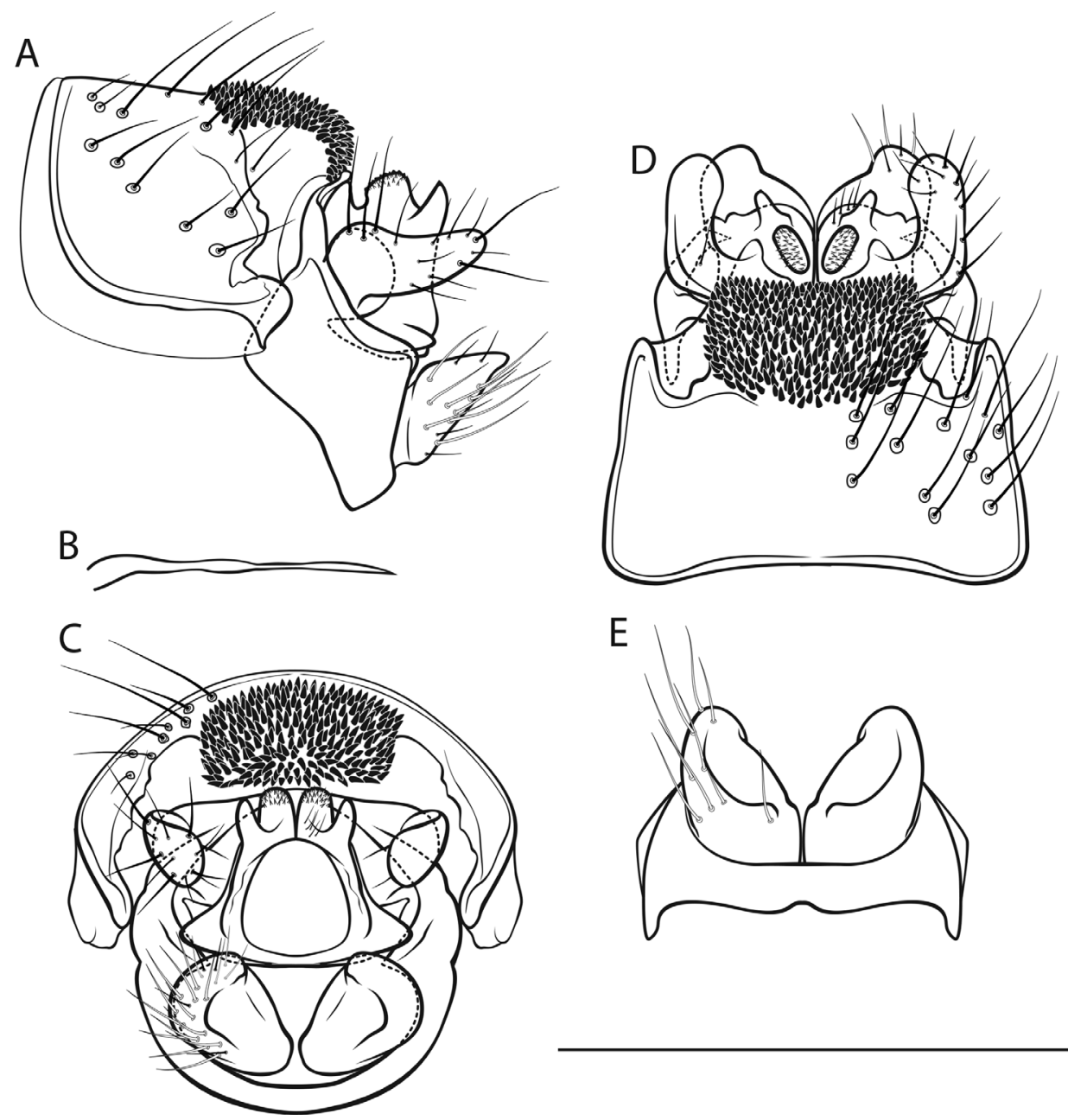

E

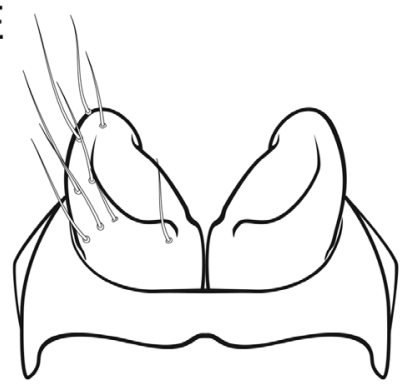

Figure 3. Male genitalia of Cryptothrix nebulicola. A left lateral view B paramere, lateral view $\mathbf{C}$ caudal view $\mathbf{D}$ dorsal view $\mathbf{E}$ ventral view. Scale bar denotes $1 \mathrm{~mm}$. Del. Vitecek.

Female depicted by Schmid (1956), Malicky (2004); larva in key presented by Waringer and Graf (2011), Vitecek et al. (in press); pupa unknown.

Distribution. Regionally in the Western Alps (ecoregion 4) (Fig. 11).

\section{Drusus chrysotus Rambur, 1842}

Fig. 4

Material examined. 12 males: Austria, Krumbach, Soboth; N46.723, E15.0555; leg. Graf; 20.V.2004; in coll. WG.

Type locality. France, Rhône-Alpes, Haute-Savoie, Chamonix valley. 

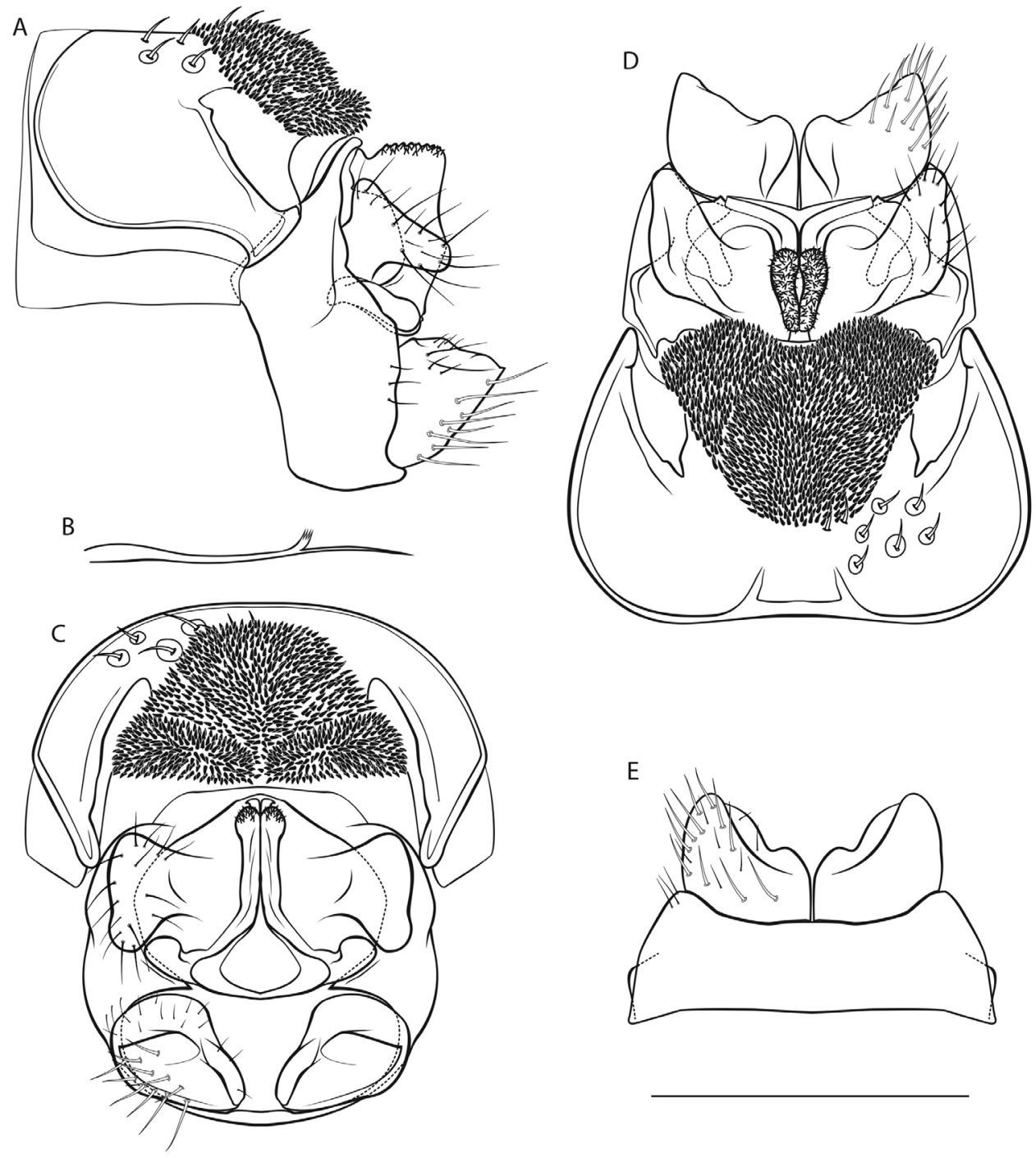

Figure 4. Male genitalia of Drusus chrysotus. A left lateral view B paramere, lateral view C caudal view D dorsal view E ventral view. Scale bar denotes $1 \mathrm{~mm}$. Del. Vitecek.

Description. Adults. Habitus: light brown to yellow; sternites and tergites light brown, abdominal tergite VII with distinct saddle; cephalic and thoracic setal areas pale; cephalic and thoracic setation blond, abdominal setation scarce, short, dark; legs fawn, proximally darker; haustellum and intersegmental integument pale, whitish; wings light brown to yellow with dark setae on veins and blond setae on membrane. Male maxillary palp 3-segmented; forewing length 14-16 mm; spur formula 1-3-3.

Male genitalia (Fig. 4). Tergite VIII light brown, with short, pale, translucent setae; spinose area in lateral view with distinct dorsal protrusion and dorsomedial caudal 
protrusion, in dorsal and caudal views tripartite; flanked by membraneous, less sclerotized areas. Segment IX in lateral view ventrally irregular concave distally; dorsally approximately as wide as ventrally in caudal view; with distinct approximately subtriangular, rounded protrusion in dorsal half (best seen in dorsal and ventral views). Superior appendages in lateral view curved obtusely ventrocaudad in proximal third, proximally with distinct dorsocranial protrusion, approximately as long as high, in dorsal view proximally concave medially; medial transverse section oval. Intermediate appendages in lateral view medially protruding caudad, dorsally with long, rough tip; in dorsal view fused into approximately heart-shaped, centrally indented structure; in caudal view ventrally broad with bulbous lateral protrusions, dorsally narrow, fused. Inferior appendages in lateral view conical, short; in ventral and dorsal views blunt, with blunt, short medial protrusion and slight notch; in ventral view with longitudinal groove delimiting medial lobe. Parameres simple with several tines on common base in distal third.

Female depicted by Schmid (1956), Malicky (2004); larva in key presented by Waringer and Graf (2011), Vitecek et al. (in press); pupa described in Bohle (1987).

Distribution. This species is widely distributed, occuring in and around the Alpine arc (ecoregion 4), the Western and Central Highlands (ecoregions $8 \& 9$ ) and was also found in the northern part of the Dinaric Alps (ecoregion 5) (Fig. 11).

\section{Drusus discolor Rambur, 1842}

Fig. 5

Material examined. 3 males: France, Mt. Canigou; N42.4864, E2.4139; leg. Graf; 12.VII.2012; in coll. WG. 2 males: France, St. Pierre de la Martin; N42.9597, E0.8290; leg. Graf; 22.VII.2012; in coll. WG. 7 males: Austria, Gurkursprung; leg. Wieser; 13.VII.1997; in coll. WG. 22 males: Switzerland, Val Munstair; N46.5852, E10.4544; leg. Graf; 20.VII.2006; in coll. WG. 1 male: Montenegro, Brodavac, right tributary of Peručica; N42.6859, E19.7364; leg. A. Previšić; 10.VII.2013; in coll. AP.

Type locality. France, Rhône-Alpes, Haute-Savoie, Chamonix valley.

Description. Adults. Habitus fawn to brown; sternites and tergites fawn to brown; cephalic and thoracic setal areas pale; cephalic, thoracic and abdominal setation blond; legs fawn, proximally darker; haustellum and intersegmental integument pale, whitish; wings blond-brown, with blond-brown setae on veins and blond setae on membrane. Male maxillary palp 3-segmented; forewing length $12-15 \mathrm{~mm}$, spur formula 1-3-3.

Male genitalia (Fig. 5). Tergite VIII light brown, setation scarce, in lateral view with distinct cranial dorsal protuberance; spinose area in lateral view with distinct dorsal protrusion and dorsomedial caudal protrusion, in dorsal view suboval, caudally straight; flanked by membraneous, less sclerotized areas. Segment IX in lateral view ventrally distinctly concave distally; in caudal view dorsally approximately as wide as ventrally; with a distinct, caudally straight rounded protrusion indorsal half (best seen in ventral view). Superior appendages in lateral view suboval, curved obtusely caudad in proximal half, proximal 

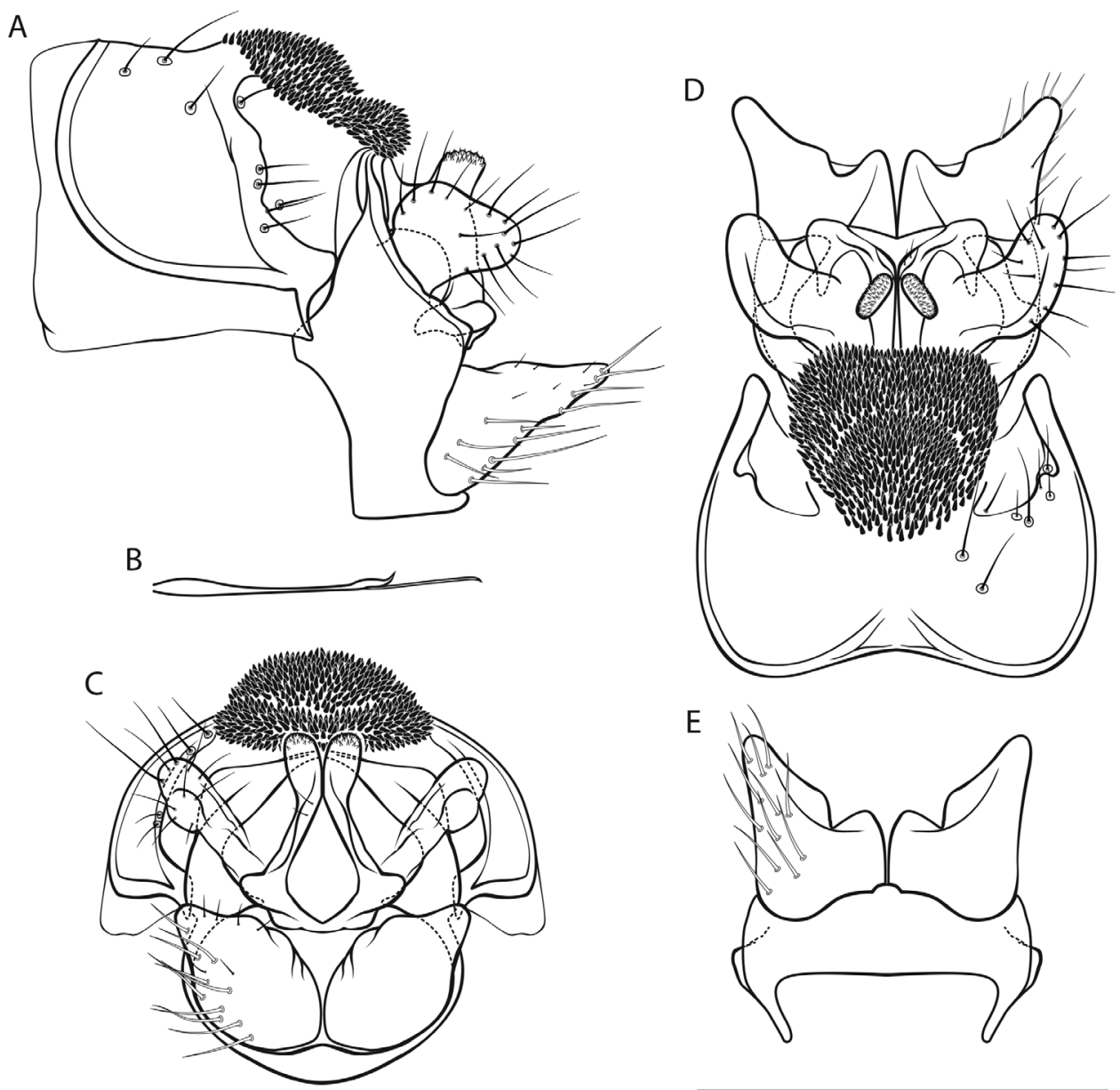

Figure 5. Male genitalia of Drusus discolor. A left lateral view B paramere, lateral view C caudal view D dorsal view E ventral view. Scale bar denotes $1 \mathrm{~mm}$. Del. Vitecek.

half with distinct dorsal protrusion, approximately as long as high; in dorsal view medially concave; medial transverse section suboval. Intermediate appendages in lateral view medially approximately straight, dorsally with rounded, rough tip; in dorsal view tips separate, oval, distally converging; in caudal view approximately triangular with dorsally diverging tips. Inferior appendages in lateral view conical; in ventral and dorsal views with distinct medial protrusion and distinct notch; in ventral view with longitudinal groove delimiting medial lobe. Parameres simple with single bulbously based tine in distal third.

Female depicted by Schmid (1956), Malicky (2004); larva in key presented by Waringer and Graf (2011), Vitecek et al. (in press); pupa unknown.

Distribution. This species is one of the most widespread Drusinae species, covering all major European mountain ranges from the Carpathians to the Pyrenees (ecoregions 1-10) (Fig. 11). 


\section{Drusus macedonicus Schmid, 1956}

Fig. 6

Material examined. 1 male: Macedonia, Jablanica Mt., Labunište; N41.271841, E20.558136; leg. Kučinić and Krpač; 19.IX.2013; in coll. MK. 1 male: Macedonia, Pelister Mt., springs of Caparska reka; N41.003889, E21.167944; leg. Graf and Previšić; 07.VII.2010; in coll. WG.

Type locality. Macedonia, Pelister Mountains.

Description. Adults. Habitus yellow; sternites and tergites fawn; cephalic and thoracic setal areas pale; cephalic and thoracic setation blond, abdominal setation scarce, blond; legs fawn; haustellum and intersegmental integument pale, whitish; wings yellow with blond setae on veins and membrane. Male maxillary palp 3-segmented; forewing length $10-12 \mathrm{~mm}$; spur formula 1-3-3.

Male genitalia (Fig. 6). Tergite VIII fawn, setation lateral, scarce; spinose area in lateral view approximately flat, in dorsal view suboval, tapering cranially; flanked by membraneous, less sclerotized areas. Segment IX in lateral view ventrally deeply concave distally, with distinct medial and ventral caudad protrusion; in caudal view slightly wider dorsally than ventrally; with sharp, caudally approximately straight protrusion in dorsal half (best seen in dorsal and ventral views). Superior appendages in lateral view irregularly suboval, curved obtusely caudad in proximal quarter, proximally with an irregular dorsal and irregular ventral protuberance, longest in anterioposterior axis: approximately 2.5 times longer than high; in dorsal view proximally slightly concave medially; medial transverse section suboval. Intermediate appendages in lateral view with two rough tips: 1 curved dorso-posteriorly, 1 central, rounded; in dorsal view posterior tips adjacent, parallel; in caudal view subtriangular with slender lateral projections. Inferior appendages in lateral view approximately conical, proximally wide, distally slender; in ventral and dorsal views with medial tip and notch, separated by slight notch; in ventral view with longitudinal groove delimiting medial lobe. Parameres simple, with single dorsal tine in distal third.

Female depicted by Schmid (1956), Malicky (2004); larva in key presented by Vitecek et al. (in press); pupa unknown.

Distribution. Micro-endemic of the Pelister and Jablanica Mountains, Hellenic Western Balkans (ecoregion 6) (Fig. 11).

\section{Drusus meridionalis Kumanski, 1973}

Fig. 7

Material examined. 10 males: Bulgaria, Vihren, Pirin Mountains, Okotovo-Banserishka, marshy spring; N41.7389, E23.4462; leg. Keresztes, Török, Kolcsár; 23.VIII.2013; in coll WG.

Type locality. Bulgaria, Rila and Pirin Mountains.

Description. Adults. Habitus yellow to brown; sternites and tergites yellow to brown; cephalic and thoracic setal areas pale; cephlic and thoracic setation blond, ab- 

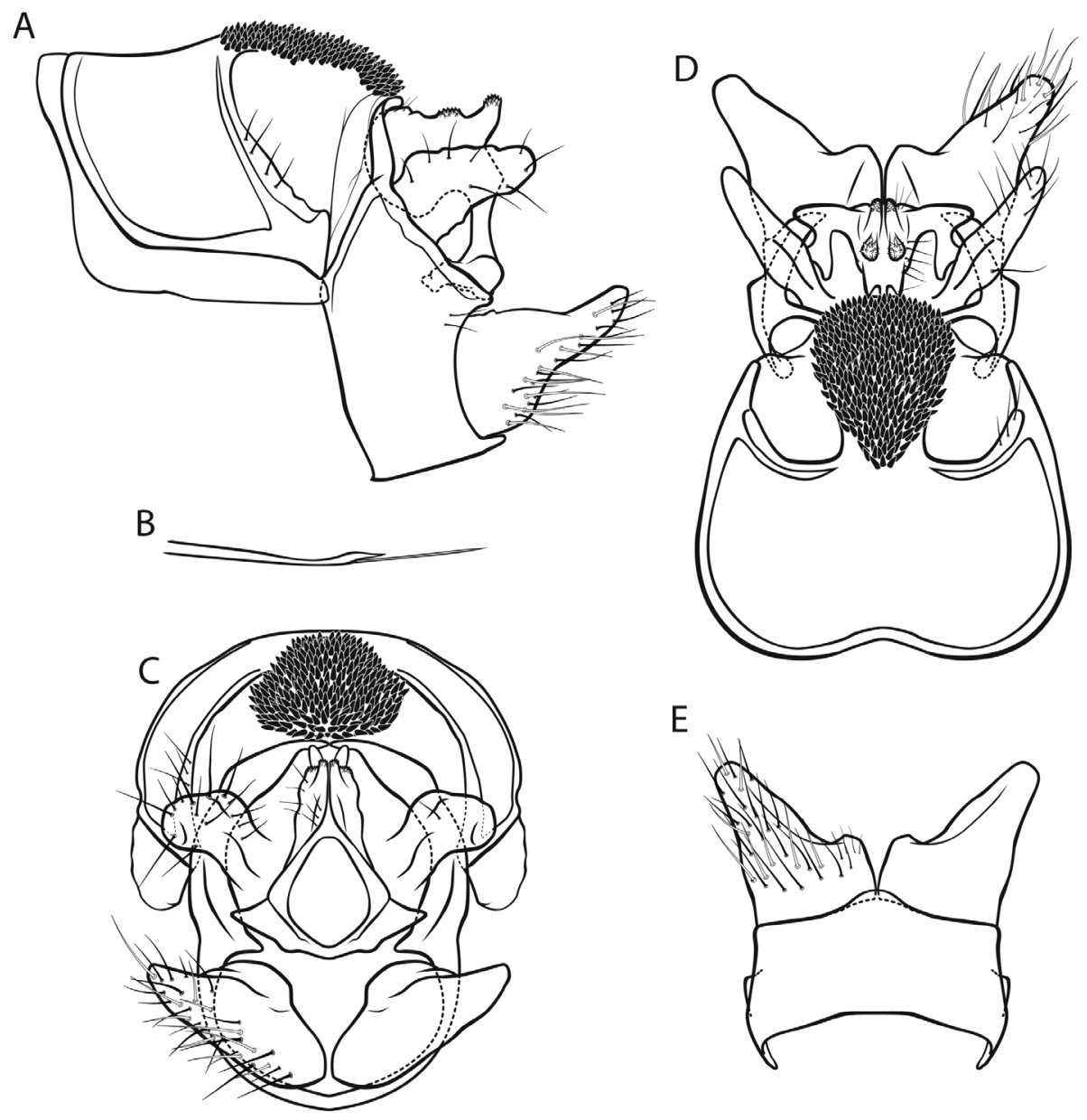

E

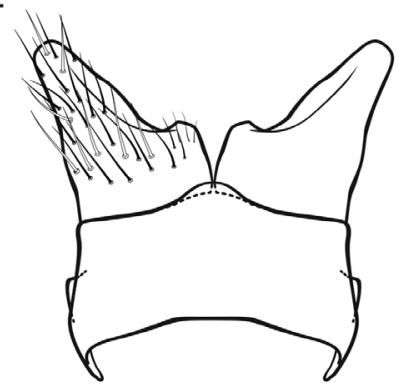

Figure 6. Male genitalia of Drusus macedonicus. A left lateral view B paramere, lateral view C caudal view $\mathbf{D}$ dorsal view $\mathbf{E}$ ventral view. Scale bar denotes $1 \mathrm{~mm}$. Del. Vitecek.

dominal setation scarce, short, dark; legs yellow to light brown, proximally darker; haustellum and intersegmental integument pale, whitish; wings yellow to fawn, with blond setae on veins and membrane. Male maxillary palp 3-segmented. Forewing length 12-14 mm; spur formula 1-3-3.

Male genitalia (Fig. 7). Tergite VIII yellow to brown, setae absent; spinose area in lateral view approximately flat, in dorsal view suboval, somewhat rectangular cranially; flanked by membraneous, less sclerotized area bearing single seta. Segment IX in lateral view ventrally slightly concave distally; in caudal view wider ventrally than dorsally; with distinct, approximately triangular, rounded protrusion in dorsal half (best seen in dorsal view). Superior appendages in lateral view suboval, curved obtusely caudad in proximal third, proximally with distinct dorsal protrusion, longest in anterioposterior axis: approximately 3 times longer 

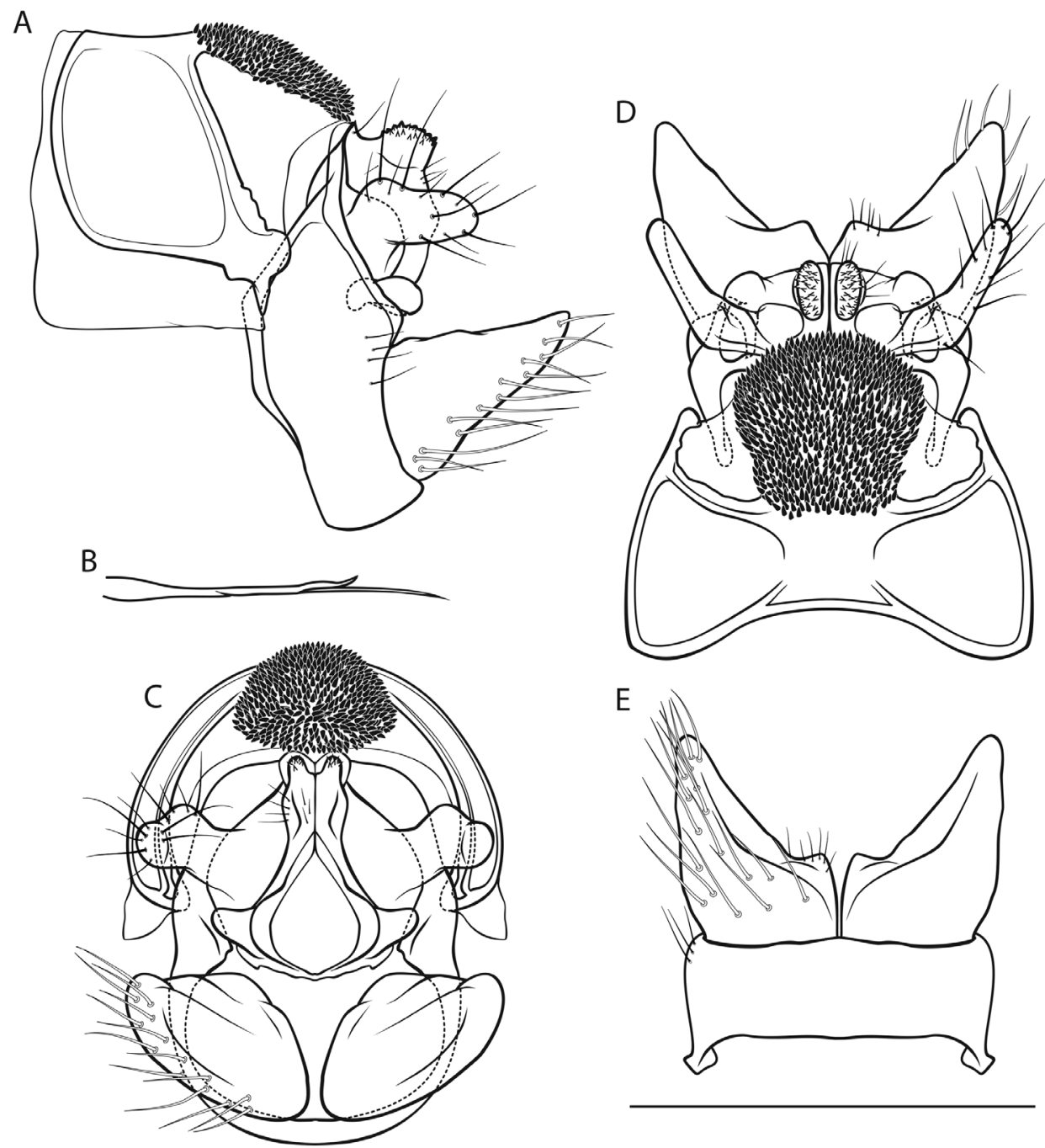

Figure 7. Male genitalia of Drusus meridionalis. A left lateral view B paramere, lateral view C caudal view $\mathbf{D}$ dorsal view $\mathbf{E}$ ventral view. Scale bar denotes $1 \mathrm{~mm}$. Del. Vitecek.

than high; in dorsal view proximally slightly concave medially; medial transverse section oval. Intermediate appendages in lateral view with rounded, rough tip; in dorsal view 2 separate parallel tips, each oval, rough; in caudal view subtriangular, dorsally with 2 separate tips. Inferior appendages in lateral view conical; in ventral and dorsal views slender with minute subtriangular medial protrusion and shallow notch; in ventral view with longitudinal groove delimiting medial lobe. Parameres simple, with single, bulbously based tine in distal third.

Female depicted by Kumanski (1973), Malicky (2004); larva in key presented by Vitecek et al. (in press); pupa unknown.

Distribution. Regionally in the Eastern Balkans (ecoregion 7) (Fig. 11). 
Comments. This species was first described as a subspecies of $D$. romanicus, but was elevated to species rank (Vitecek et al. in press). It is morphologically distinct from $D$. romanicus, disjunct in distribution, and was recovered as a well-separated clade from $D$. romanicus in the phylogenetic analyses of Pauls et al. (2009) and Vitecek et al. (in press).

\section{Drusus muelleri McLachlan, 1868}

Fig. 8

Material examined. 1 male: Switzerland, Furkapass; N46.5888, E8.4327; leg. Graf; 21.VII.2006, in coll. WG.

Type locality. Switzerland, Canton of Uri, Hospental.

Description. Adults. Habitus dark; sternites and tergites brown; cephalic and thoracic setal areas pale, cephalic and thoracic setation blond, abdominal setation scarce, short, dark; coxa, trochanter, femur brown, tibia and tarsi fawn; haustellum and intersegmental integument pale, whitish; wings brown, smoky, with dark setae on veins and blond setae on membrane. Male maxillary palp 3-segmented; Forewing length 11-13 mm (Malicky 2004); spur formula 1-3-3.

Male genitalia (Fig. 8). Tergite VIII brown, setae absent; spinose area in lateral view convex with caudal ventral lobe, in dorsal view suboval with small medial protrusion; flanked by membraneous, less sclerotized areas. Segment IX in lateral view ventrally slightly concave distally; in caudal view wider dorsally than ventrally; with sharp caudally straight subtriangular protrusion in the dorsal half (best seen in dorsal and ventral views). Superior appendages in lateral view irregular, curved obtusely caudad in proximal quarter, proximally distinctly dilated, distally clavate, longest in anterioposterior axis: approximately 5 times longer than high; in dorsal view the proximal third concave medially; medial transverse section circular. Intermediate appendages in lateral view with long, rounded rough tip; in dorsal view tips separate, approximately parallel, proximally bulbous; in caudal view subtriangular. Inferior appendages in lateral view subtriangular, ventrally irregular, proximally sightly concave dorsally; in ventral and dorsal views broad, with small subtriangular medial protrusion and distinct notch; in ventral view with longitudinal groove delimiting medial lobe; in caudal view broad. Parameres simple, with single dorsal tine in distal third.

Female depicted by Schmid (1956), Malicky (2004), larva in key presented by Waringer and Graf (2011), Vitecek et al. (in press); pupa unknown.

Distribution. Regionally in the Western Alps (ecoregion 4) (Fig. 11).

\section{Drusus romanicus Murgoci and Botosaneanu, 1953}

Fig. 9

Material examined. 1 male: Romania, Apuseni Mts., Garda de Sus, tributary of Ariesul Mare; N46.4508, E22.7982; leg. Oláh, Bajka, Balogh, Borics; 29.V.2013; in coll. 

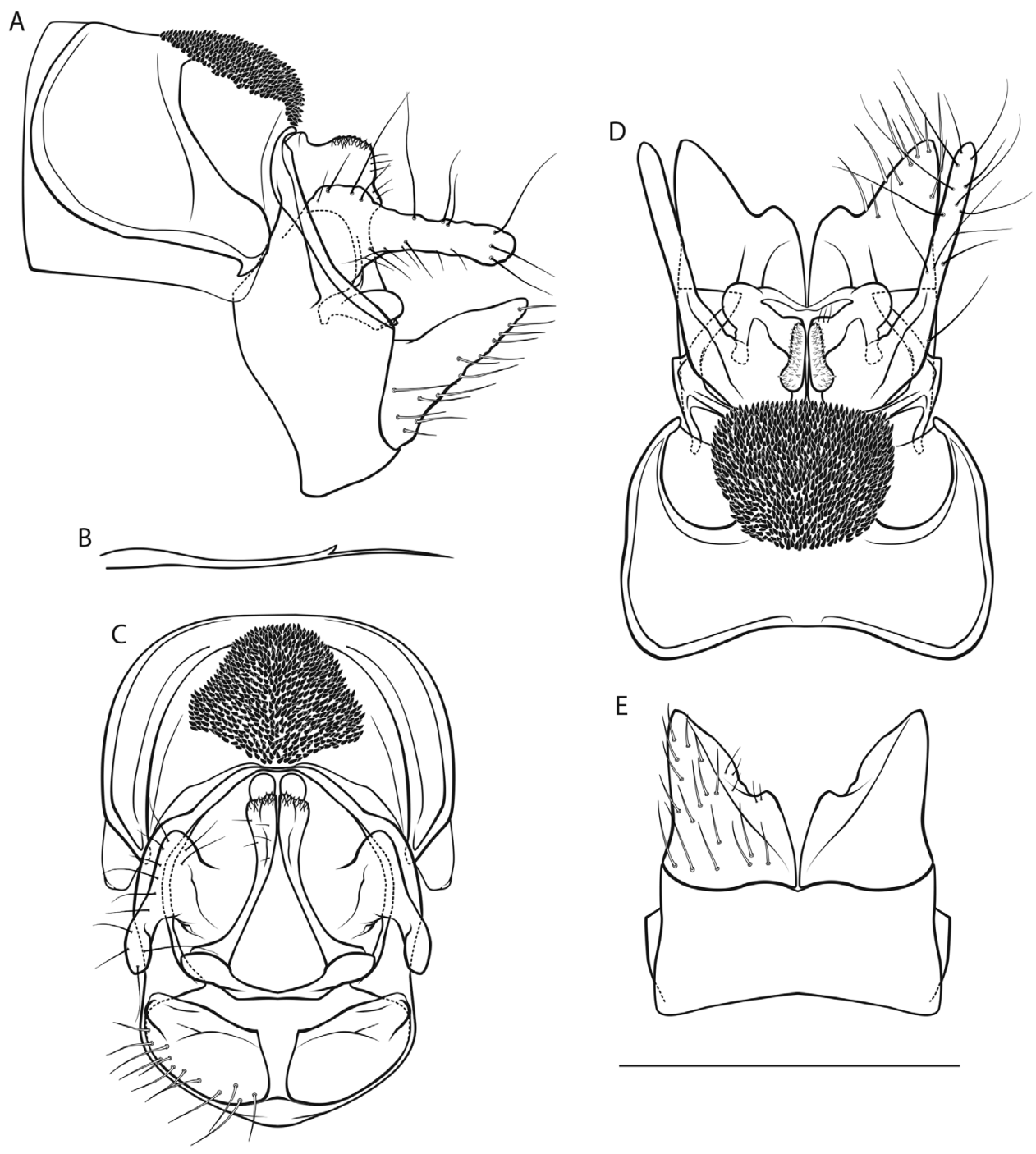

$\mathrm{E}$

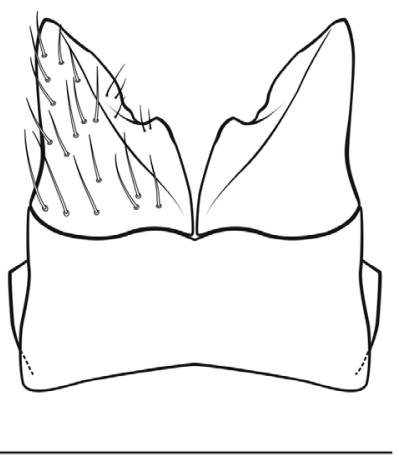

Figure 8. Male genitalia of Drusus muelleri. A left lateral view B paramere, lateral view $\mathbf{C}$ caudal view D dorsal view $\mathbf{E}$ ventral view. Scale bar denotes $1 \mathrm{~mm}$. Del. Vitecek.

WG. 1 male: Romania, Apuseni Mts., Muntii Giaului, Stiunea Muntele Baisorii, Lupinus stream; leg. Oláh, Balogh, Fekete; 18.VI.2013; in coll. WG. 1 male: Romania, Retezat Mts, Bucara Stream, 150 m below Bucara lake; N45.3570, E22.8753; leg. Bajka, Balogh, Borics, Borics; 10.VIII.2013; in coll. WG.

Type locality. Romania, Carpathian Mountains, spring areas of the Ialomita stream.

Description. Adults. Habitus brown to light brown; sternites and tergites brown to light brown; cephalic and thoracic setal areas pale; cephalic, thoracic and abdominal 

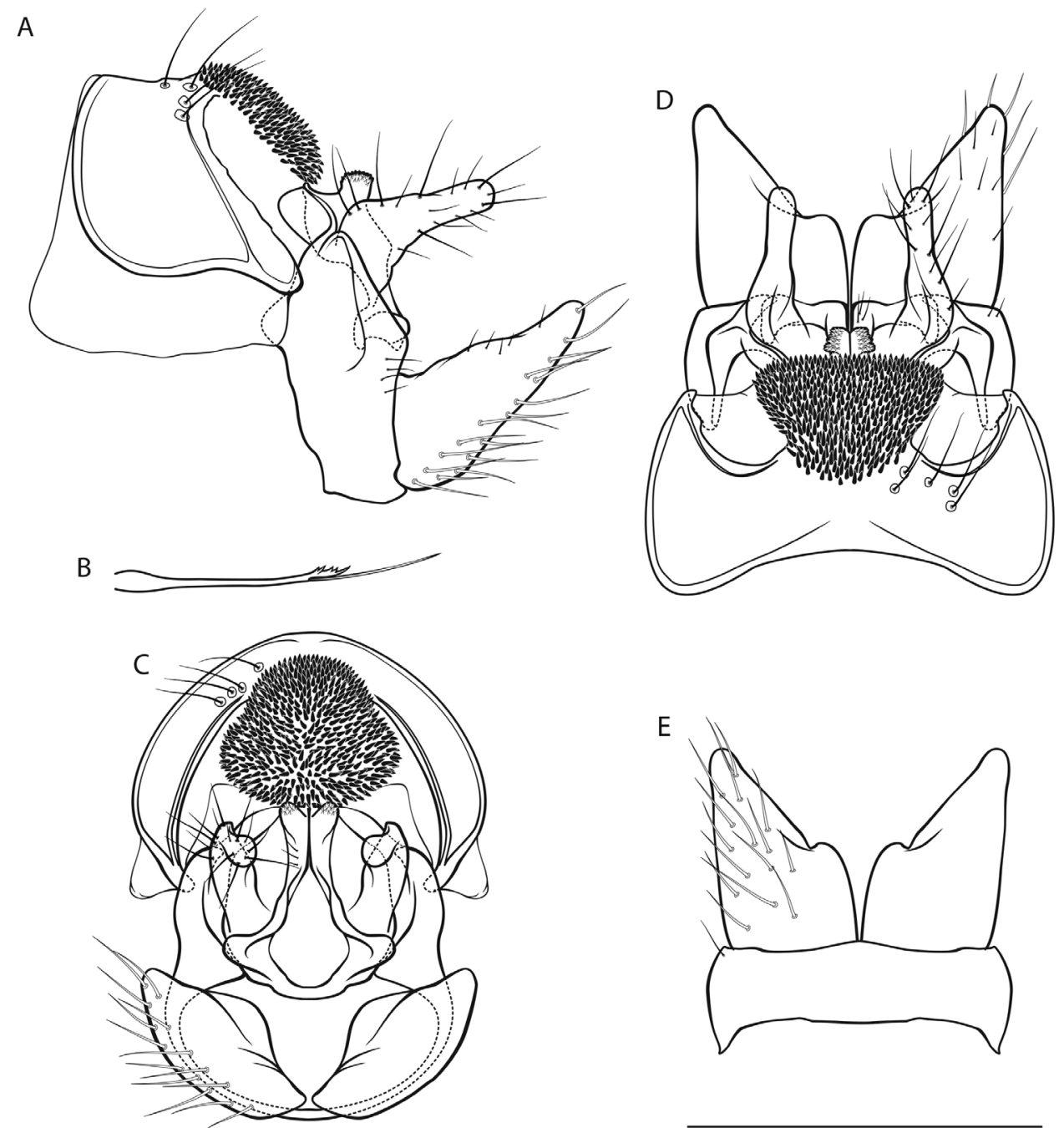

Figure 9. Male genitalia of Drusus romanicus. A left lateral view B paramere, lateral view C caudal view D dorsal view $\mathbf{E}$ ventral view. Scale bar denotes $1 \mathrm{~mm}$. Del. Vitecek.

setation blond; legs light brown, proximally darker; haustellum and intersegmental integument pale, whitish; wings brown, proximally lighter, with blond setae on veins and membrane. Male maxillary palp 3-segmented; forewing length $12-14 \mathrm{~mm}$; spur formula 1-3-3.

Male genitalia (Fig. 9). Tergite VIII brown, setae present; spinose area in lateral view approximately flat with slight dorsal protrusion, in dorsal view suboval, distally straight; flanked by membraneous, less sclerotized areas. Segment IX in lateral view dorsally with distinct notch distally, ventrally irregularly concave distally; in caudal 
view ventrally wider than dorsally; with distinct subtriangular rounded protrusion in dorsal half (best seen in dorsal view). Superior appendages in lateral view elongate suboval, curved obtusely dorsocaudad in proximal quarter, proximally with round dorsal protrusion and irregular ventral protrusion, longest in anterioposterior axis: approximately 4.5 times longer than high; in dorsal view proximally distinctly concave medially; medial transverse section circular. Intermediate appendages in lateral view with rounded, rough tip; in dorsal view tips separate, laterally diverging; in caudal view subtriangular. Inferior appendages in lateral view conical, long, dorsally irregular, proximally slightly concave dorsally; in ventral and dorsal views proximal half robust, distal half slender with slight medial protrusion and shallow notch. Parameres simple, with medial hook-shaped tip bearing several smaller tines.

Female and pupa unknown; larva in key presented by Vitecek et al. (in press).

Distribution. Regionally in the Western and Southern Carpathians (ecoregion 10) (Fig. 11).

\section{Drusus siveci Malicky, 1981}

Fig. 10

Material examined. 5 males: Bosnia and Herzegovina, Sutjeska National Park, stream close to Čermerno; N43.2650, E18.5927; leg. Previšić, Miliša; 04.VII.2012; in coll. AP.

Type locality. Montenegro, Andrijevica, Gnjili Potok.

Description. Adults. Habitus yellow to fawn; sternites and tergites fawn; cephalic and thoracic setal areas pale; cephalic, thoracic and abdominal setation blond; legs yellow to fawn; haustellum and intersegmental integument pale, whitish; wings fawn, with blond to brown setae on veins and blond setae on membrane. Male maxillary palp 3-segmented, forewing length 10-12 mm, spur formula 1-3-3.

Male genitalia (Fig. 10). Tergite VIII fawn, setation concentrated dorsally and posterolaterally, with slight dorsal protrusion; spinose area in lateral view approximately flat, in dorsal view oval; flanked by membraneous, less sclerotized areas. Segment IX in lateral view with medial caudad protrusion, ventrally irregularly concave distally; in caudal view wider dorsally than ventrally; with distinct rounded triangular protrusion in dorsal half (best seen in dorsal and ventral views). Superior appendages in lateral view suboval, curved obtusely caudad in proximal half, proximal half with distinct rounded protrusion, in dorsal view slightly concave medially; medial transverse section subcircular. Intermediate appendages in lateral view with pointed, hook-like tip arching dorsad; in dorsal and caudal views the tips fused; in caudal view subtriangular. Inferior appendages in lateral view conical, short, blunt, posteroventrally somewhat concave; in ventral view with medial protrusion and distinct notch. Parameres simple, with single bulbously based tine in distal third.

Female and pupa unknown; larva in key presented by Vitecek et al. (in press).

Distribution. Micro-endemic of the Dinaric Western Balkans (ecoregion 5) (Fig. 11). 

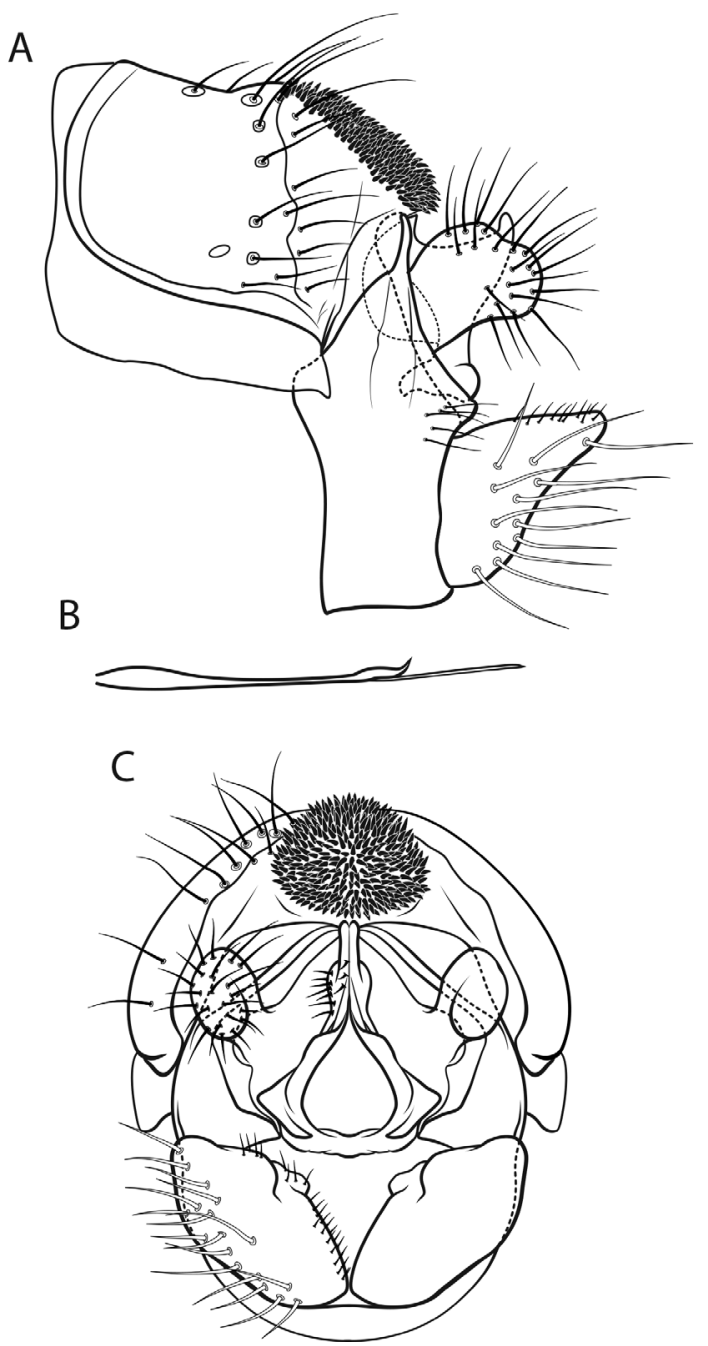

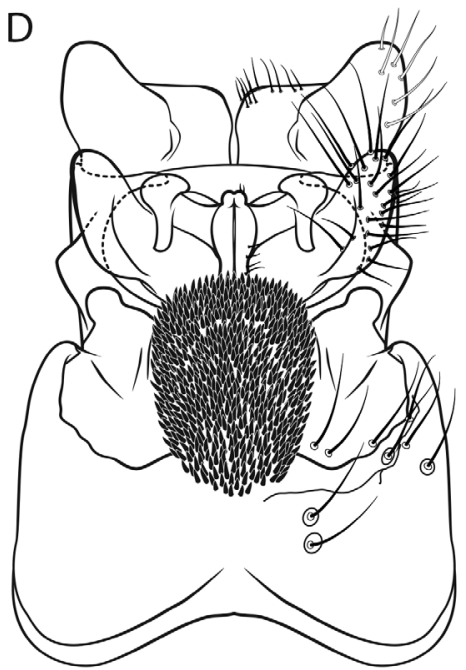

E

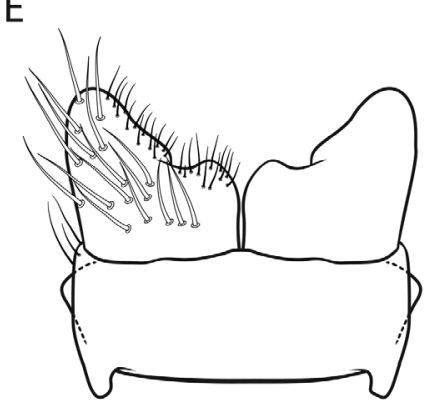

Figure 10. Male genitalia of Drusus siveci. A left lateral view B paramere, lateral view C caudal view D dorsal view $\mathbf{E}$ ventral view. Scale bar denotes $1 \mathrm{~mm}$. Del. Vitecek.

\section{Discussion}

\section{Drusinae micro-endemics of the Western Balkans}

Morphology of the new species as well as molecular phylogenetic analyses (Vitecek et al. in press) suggest that the new species belong to the monophyletic clade of filtering carnivorous Drusinae sensu Pauls et al. (2008), comprising Drusus discolor, D. muelleri, D. chrysotus, D. siveci, D. romanicus, D. meridionalis and Cryptothrix nebulicola. The Drusus species described here are similar to D. macedonicus Schmid. However, they differ distinctly in the morphology of the male genitalia, particularly the intermediate 


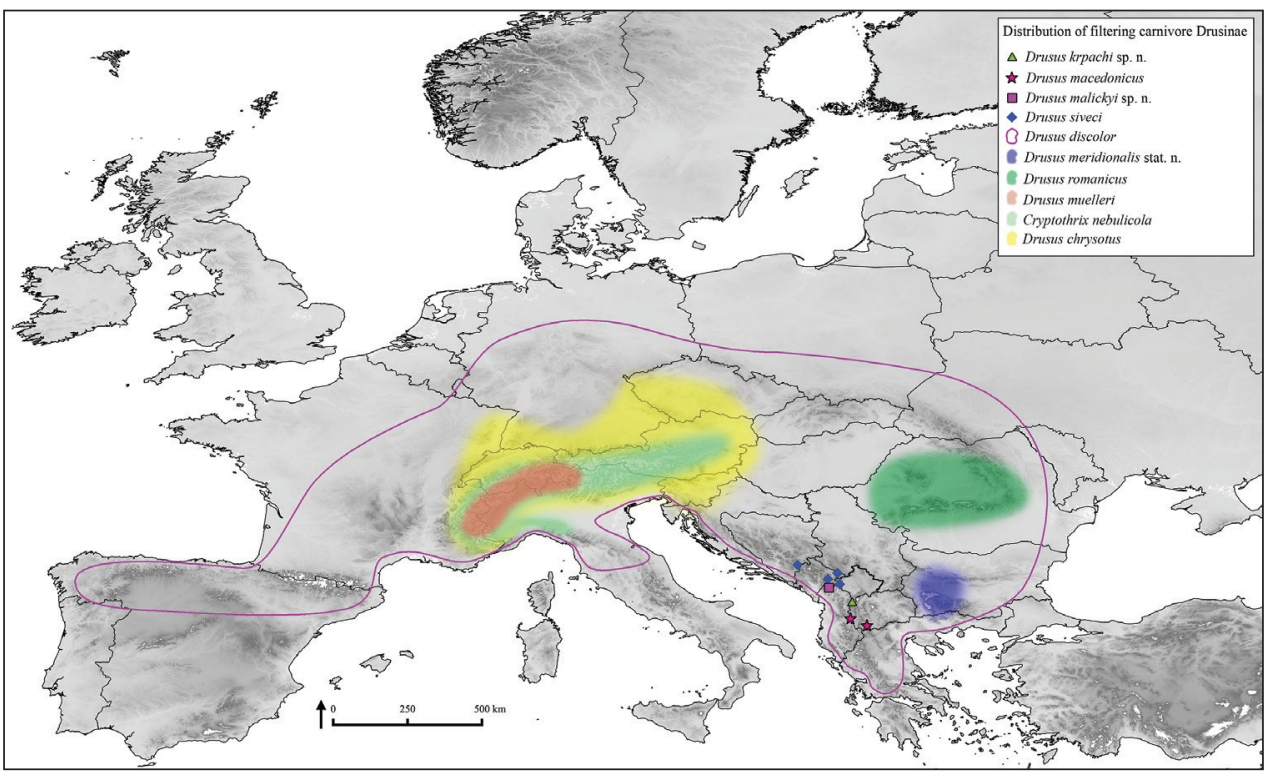

Figure I I. Distribution of filtering carnivore Drusinae. Single records of endemic species are depicted as symbols, stroked or filled areas denote ranges of more widely distributed species with a higher number of occurrence records.

appendages, and are discretely distributed. Also, they are highly supported in phylogenetic analysis and form a highly supported clade comprising (D. malickyi $+(D$. krpachi + D. macedonicus) in the phylogenetic analysis of Vitecek et al. (in press). To our knowledge, the new species are small-scale endemics restricted to single mountain ranges.

Interestingly, the type localities of the new species are close to the known range of D. macedonicus (Fig. 11). Such small-scale distribution of distinct Drusinae species is well documented from the Western Balkans (Marinković-Gospodnetić 1976; Kučinić et al. 2011a; Oláh 2010, 2011; Oláh and Kovács 2013; Previšić et al. 2014a, b; Vitecek et al. 2015). Similarly, other taxa exhibit comparable distribution patterns, in which single mountain ranges represent the range of a species, or haplogroups (Ursenbacher et al. 2008, Stevanović et al. 2009, Zogaris et al. 2009, Karaman et al. 2011). The intriguing distribution patterns exhibited by some groups of species potentially result from the geological history of the region and historic and present-day climate conditions. Small-scale speciation of Drusinae presumably is facilitated by intrinsic traits of the subfamily, such as their occurrence at higher elevations (Pauls et al. 2006, 2009), a putatively low long-distance dispersal potential (Müller-Peddinghaus 2011, Geismar et al. 2015), and might be further enhanced by habitat fragmentation, e.g., by regional karstification. Occurrence of Drusinae could therefore serve as proxy to occurrence of other aquatic invertebrate taxa, particularly to crenobiont taxa exhibiting the same or similar traits. 


\section{Western Balkan aquatic diversity}

The Western Balkans represent a hot-spot of species richness and endemicity in Europe (Griffiths et al. 2004, Guéorguiev 2007, Kenyeres et al. 2009, Jaskuła 2011). In particular, the faunas of isolated habitats such as coldwater springs and streams, caves or the profundal zone of large lakes contribute to high species richness in the region (Petkovski et al. 2009, Wilke et al. 2010, Pešić and Glöer 2013). Such taxa probably are more susceptible to factors promoting speciation, such as climatic and geological processes (e.g., karstification, see Previšić et al. 2009, 2014b), especially if their dispersal potential is low.

The description of the two new micro-endemic Drusus species increases the number of Western Balkan Drusinae species. Drusinae richness in the Western Balkans currently comprises 40 species including 13 species (30\%) that were discovered since 2010, of which 32 are endemic to the Western Balkans (Graf et al. 2008; Oláh 2010, 2011; Schmidt-Kloiber and Hering 2012; Oláh and Kovács 2013; Previšić et al. 2014b; Vitecek et al. 2015; Ibrahimi et al. pers. comm.; this study).

Thus, endemism rates of Western Balkan Drusinae are high, and are further augmented by the description of the two new micro-endemic Drusus species. Global and anthropogenic habitat changes are among the greatest threats to micro-endemic and endemic freshwater species (Hering et al. 2009, Tierno de Figueroa et al. 2010, Bálint et al. 2011, Conti et al. 2014). Water extraction for human consumption intensified by tourism, agriculture, and hydroelectricity are the primary modes of global anthropogenic habitat modification of freshwaters (Foster 1991, Polhemus 1993, Dudgeon 2006). Hydropower plants were identified as the greatest threat to European freshwater biodiversity (Freyhof 2012, Schwarz 2012, Zarfl et al. 2014, http://riverwatch.eu).

Recent published taxonomic works treating the Western Balkans, including the present one describing two new micro-endemic Drusus species, have demonstrated the significance of the region for European biodiversity. However, progressing socioeconomic change and anthropogenic habitat modification threaten the freshwater biodiversity of the Western Balkans, and potentially will result in the loss of yet-to-be discovered species.

\section{Acknowledgments}

We are most grateful to G. Puskas, Budapest (Hungary), and V. Krpač, Skopje (Macedonia), for donating their valuable material. This contribution is result of research on the project "The Drusinae (Insecta: Trichoptera) in a world of global change" (project number P23687-B17, PI: J. Waringer), funded by the Austrian Science Fund (FWF). Distribution data used in this contribution were partly extracted from a preliminary version of the Distribution Atlas of European Trichoptera, (DAET), collated as part of the BioFresh project (supported by the EU Directive $7^{\text {th }}$ framework programme, contract number 226874); Peter Neu, Kasel (Germany), and contributors to the DAET are 
thanked for their help with distribution data and permission to use their data on sampling localities. Ian Stocks and Ralph Holzenthal are thanked for their rigorous reviews on an earlier version of the manuscript, and very quick handling of the manuscript.

\section{References}

Bálint M, Domisch S, Engelhardt CHM, Haase P, Lehrian S, Sauer J, Theissinger K, Pauls SU, Nowak C (2011) Cryptic biodiversity loss linked to global climate change. Nature Climate Change 1: 313-318. doi: 10.1038/nclimate1191

Bănărescu PM (2004) Distribution pattern of the aquatic fauna of the Balkan peninsula. In: Griffiths HI, Kryštufek B, Reed J (Eds) Balkan Biodiversity. Kluwer Academic Publishers, Dordrecht, 203-217. doi: 10.1007/978-1-4020-2854-0_12

Bianco PG (1998) Diversity of Barbinae fishes in southern Europe with description of a new genus and a new species (Cyprinidae). Italian Journal of Zoology 65(S1): 125-136. doi: 10.1080/11250009809386804

Bohle HW (1987) Drift-fangende Köcherfliegen-Larven unter den Drusinae (Trichoptera: Limnephilidae). Entomologia generalis 12(12-3): 119-132.

Bohlen J, Perdices A, Doadrio I, Ecnomidis PS (2006) Vicariance, colonisation, and fast local speciation in Asia Minor and the Balkans as revealed from the phylogeny of spined loaches (Osteichthyes; Cobitidae). Molecular Phylogenetics and Evolution 39: 552-561. doi: 10.1016/j.ympev.2005.12.007

Chiari M, Djeric N, Garfagnoli F, Hrvatović, Krstić M, Levi N, Malasoma A, Marroni M, Menna F, Nirta G, Pandolfi L, Principi G, Saccani E, Stojadinovi Trivić B (2011) The geology of the Zlatibor-Maljen area (Western Serbia): a geotraverse across the ophiolites of the Dinaric-Hellenic collisional belt. Ofioliti 36(2): 139-166.

Conti L, Schmidt-Kloiber A, Grenouillet G, Graf W (2013) A trait-based approach to assess the vulnerability of European aquatic insects to climate change. Hydrobiologia 721(1): 297-315. doi: 10.1007/s10750-013-1690-7

Deltshev C (2008) Faunisitc diversity and zoogeography of cave-dwelling spiders on the Balkan Peninsula. Advances in Arachnology and Developmental Biology 12: 327-348.

Dudgeon D, Arthington AH, Gessner MO, Kawataba ZI, Knowler DJ, Lévêque C, Naiman RJ, Prieur-Richard AH, Soto D, Stiassny MLJ, Sullivan CA (2006) Freshwater biodiversity: importance, threats, status and conservation challenges. Biological Reviews 81: 163-182. doi: 10.1017/S1464793105006950

Eastwood WJ (2004) East Mediterranean vegetation and climate change. In: Griffiths HI, Kryštufek B, Reed J (Eds) Balkan Biodiversity. Kluwer Academic Publishers, Dordrecht, 25-48. doi: 10.1007/978-1-4020-2854-0_3

Foster GN (1991) Conserving insects of aquatic and wetland habitats, with special reference to beetles. In: Collins NM, Thomas JA (Eds) The conservation of insects and their habitats. Academic Press, London, 237-262. doi: 10.1002/rrr.3450070310

Freyhof J (2012) Threatened freshwater fishes and molluscs of the Balkan, potential impact of hydropower projects. Unpublished report, ECA Watch Austria\&EuroNatur, 81 pp. 
Geismar J, Haase P, Nowak C, Sauer J, Pauls SU (2015) Local population genetic structure of the montane caddisfly Drusus discolor is driven by overland dispersal and spatial scaling. Freshwater Biology 60: 209-221. doi: 10.1111/fwb.12489

Graf W, Murphy J, Dahl J, Zamora-Muñoz C, López-Rodríguez MJ (2008) Volume 1 - Trichoptera. In: Schmidt-Kloiber A, Hering D (Eds), Distribution and Ecological Preferences of European Freshwater Organisms. Pensoft Publishers, Sofia, Moscow, 388 pp.

Graf W, Waringer, Pauls J, SU (2009) A new feeding group within larval Drusinae (Trichoptera: Limnephilidae): the Drusus alpinus Group sensu Schmid, 1956, including larval descriptions of Drusus franzi Schmid, 1956, and Drusus alpinus (Meyer-Dür, 1875). Zootaxa 2031: 53-62.

Griffiths HI, Frogley MR (2004) Fossil ostracods, faunistics and the evolution of regional biodiversity. In: Griffiths HI, Kryštufek B, Reed J (Eds) Balkan Biodiversity. Kluwer Academic Publishers, Dordrecht, 261-272. doi: 10.1007/978-1-4020-2854-0

Griffiths HI, Krystufek B, Reed JM (2004) Balkan Biodiversity. Kluwer Academic Publishers, Dordrecht, 355 pp. doi: 10.1007/978-1-4020-2854-0

Guéorguiev B (2007) Biogeography of the endemic Carabidae (Coleoptera) in the Central and Eastern Balkan Peninsula. In: Fet V, Popov E (Eds) Biogeography and Ecology of Bulgaria, Springer, Dordrecht, 297-356. doi: 10.1007/978-1-4020-5781-6_9

Hering D, Schmidt-Kloiber A, Murphy J, Lucke S, Zamora-Muñoz C, Lopez-Rodriguez MJ, Huber T, Graf W (2009) Potential impact of climate change on aquatic insects: A sensitivity analysis for European caddisflies (Trichoptera) based on distribution patterns and ecological preferences. Aquatic Sciences 71: 3-14. doi: 10.1007/s00027-009-9159-5

Ibrahimi H, Kučinić M, Vitecek S, Waringer J, Graf W, Previšić A, Bálint M, Keresztes L, Pauls S (pers. comm.) New records for the Kosovo caddisfly fauna with the description of a new species, Drusus dardanicus sp. nov. (Trichoptera: Limnephilidae). Submitted for publication at Zootaxa.

Illies J (1978) Limnofauna Europaea. A Checklist of the Animals Inhabiting European Inland Waters, with an Account of their Distribution and Ecology. 2nd Edition, Gustav Fischer Verlag, Stuttgart, 552 pp.

Jaskuła R (2011) How unique is the tiger beetle fauna (Coleoptera, Cicindelidae) of the Balkan Peninsula? ZooKeys 100: 487-502. doi: 10.3897/zookeys.100.1542

Karaman I, Hammouti N, Pavićević D, Kiefer A, Horvatović M, Seitz A (2011) The genus Troglophilus Krauss, 1879 (Orthoptera, Rhaphidophoridae) in the west Balkans. Zoological Journal of the Linnean Society 163: 1035-1063. doi: 10.1111/j.1096-3642.2011.00738.x

Kenyeres Z, Rácz IA, Varga Z (2009) Endemism hot spots, core areas and disjunctions in European Orthoptera. Acta Zoologica Cracoviensia 52B(1-2): 189-211. doi: 10.3409/ azc.52b_1-2.189-211

Klobučar GIV, Podnar M, Jelić M, Franjević D, Faller M, Štambuk A, Gottstein S, Simić V, Maguire I (2013) Role of the Dinaric karst (Western Balkans) in shaping the phylogeographic structure of the threatened crayfish Austropotamobius torrentium. Freshwater Biology 58: 1089-1105. doi: 10.1111/fwb.12110

Kryštufek B (2004) A quantitative assessment of Balkan mammal diversity. In: Griffiths HI, Kryštufek B, Reed J (Eds) Balkan Biodiversity. Kluwer Academic Publishers, Dordrecht, 79-108. doi: 10.1007/978-1-4020-2854-0_6 
Kučinić M, Previšić A, Graf W, Šeric Jelaska L, Stanić-Koštroman S, Waringer J (2011a) Larval description, genetic and ecological features of Drusus radovanovici radovanovici Marinković-Gospodnetić, 1971 (Trichoptera: Limnephilidae) with some phylogenetic and taxonomic data on the bosnicus group in the Balkan Peninsula. Deutsche Entomologische Zeitschrift 58: 136-153. doi: 10.1002/mmnd.201100010

Kučinić M, Previšić A, Stanić-Koštroman S, Graf W, Franjević M, Posilović H, Waringer J (2011b) Morphological and ecological features of Drusus larvae from the bosnicus group on the Balkan Peninsula with description of the larva of Drusus klapaleki MarinkovićGospodnetić, 1976. Zoosymposia 5: 244-254.

Kumanski K (1973) Die Unterfamilie Drusinae (Trichoptera) in Bulgarien. Tijdschrift voor Entomologie 116: 107-121.

Malicky H (2004) Atlas of European Trichoptera, Second edition. Springer, 359 pp.

Malicky H (2005) Ein kommentiertes Verzeichnis der Köcherfliegen (Trichoptera) Europas und des Mediterrangebietes. Linzer biologische Beiträge 37: 533-596.

Marinković-Gospodnetić M (1976) The differentiation of Drusus species of the group bosnicus. In: Malicky H (Ed.) Proceedings of the First International Symposium on Trichoptera, Dr. W. Junk Publishers, The Hague, 77-85. doi: 10.1007/978-94-010-1579-0_13

Médail F, Diadema K (2009) Glacial refugia influence platn diversity patterns in the Mediterranean Basin. Journal of Biogeography 36: 1333-1345. doi: 10.1111/j.13652699.2008.02051.x

Mered’a P Jr., Hoálová I, Kučera J, Zozomová-Lihová J, Letz DR, Slovák M (2011) Genetic and morphological variation in Viola suavis s.l. (Violaceae) in the Western Balkan Peninsula: two endemic subspecies revealed. Systematics and Biodiversity 9(3): 211-231. doi: $10.1080 / 14772000.2011 .603903$

Müller-Peddinghaus EH (2011) Flight-morphology of Central European caddisflies (Insecta: Trichoptera) in relation to their ecological preferences. Dr. rer. nat., University of DuisburgEssen, Essen.

Neubauer F (2002) Evolution of late Neopoterozoic to early Paleozoic tectonic elements in Central and Southeast European Alpine mountain belts: review and synthesis. Tectonophysics 352: 87-103. doi: 10.1016/S0040-1951(02)00190-7

Nielsen A (1957) A comparative study of the genital segments and their appendages in male trichoptera. Biologiske Skrifter udgivet af Det Kongelige Dankse Vedenskabernes Sleskab 8: 1-159.

Oláh J (2010) New species and new records of Palearctic Trichoptera in the material of the Hungarian Natural History Museum. Annales Historico-Naturales Musei Nationalis Hungarici 102: 65-117.

Oláh J (2011) New species and records of Balkan Trichoptera. Folia Historico Naturalia Musei Matrensis 35: 111-121.

Oláh J, Kovács T (2013) New species and new records of Balkan Trichoptera II. Folia Historico Naturalia Musei Matrensis 37: 109-121.

Pauls SU, Lumbsch HT, Haase P (2006): Phylogeography of the montane caddisfly Drusus discolor: Evidence for multiple refugia and periglacial survival. Molecular Ecology 15: 2153-2169. doi: 10.1111/j.1365-294X.2006.02916.x 
Pauls SU, Graf W, Haase P, Lumbsch HT, Waringer J (2008) Grazers, shredders and filtering carnivores - The evolution of feeding ecology in Drusinae (Trichoptera: Limnephilidae): Insights from a molecular phylogeny. Molecular Phylogenetics and Evolution 46: 776-791. doi: 10.1016/j.ympev.2007.11.003

Pauls SU, Theißinger K, Ujvarosi L, Bálint M, Haase P (2009) Population structure in two closely related, partially sympatric caddisflies in Eastern Europe: historic introgression, limited dispersal and cryptic diversity. Journal of the North American Benthological Society 28: 517-536. doi: 10.1899/08-100.1

Pešić V, Glöer P (2013) A new freshwater snail genus (Hydrobiidae, Gastropoda) from Montenegro, with a discussion on gastropod diversity and endemism in Skadar Lake. ZooKeys 281: 69-90. doi: 10.3897/zookeys.281.4409

Petkovski T, Scharf BW, Keyser D (2009) Freshwater Ostracode (Crustacea) collected from caves and the interstitial habitat in Herzegovina, NW Balkan, with the description of two new species. Bulletin de la Société des naturalistes luxembourgeois 110: 173-182.

Petrova A, Vladimirov V (2010) Balkan endemics in the Bulgarian flora. Phytologia Balcanica 16(2): 293-311.

Polhemus DA (1993) Conservation of Aquatic Insects: Worldwide crisis or worldwide threats? American Zoologist 33(6): 588-598.

Previšić A, Walton C, Kučinić M, Mitrikeski PT, Kerovec M (2009) Pleistocene divergence of Dinaric Drusus endemics (Trichoptera, Limnephilidae) in multiple microrefugia within the Balkan Peninsula. Molecular Ecology 18: 634-647. doi: 10.1111/j.1365294X.2008.04046.x

Previšić A, Graf W, Vitecek S, Kučinić M, Bálint M, Keresztes L, Pauls SU, Waringer J (2014a) Cryptic diversity of caddisflies in the Balkans: the curious case of Ecclisopteryx species (Trichoptera: Limnephilidae). Arthropod Systematics and Phylogeny 72(3): 309-329.

Previšić A, Schnitzler J, Kučinić M, Graf W, Ibrahimi H, Kerovec M, Pauls SU (2014b) Microscale vicariance and diversification of western Balkan caddisflies linked to karstification. Freshwater Science 33: 250-262. doi: 10.1086/674430

Redžić S (2011) Phytogeographic and syntaxonomic diversity of high mountain vegetation in Dinaric Alps (Western Balkan, SE Europe). Journal of Mountain Science 8: 767-786. doi: 10.1007/s11629-011-2047-1

Reed JM, Kryštufek B, Eastwood WJ (2004) The physical geography of the Balkans and nomenclature of place names. In: Griffiths HI, Kryštufek B, Reed J (Eds) Balkan Biodiversity. Kluwer Academic Publishers, Dordrecht, 9-23. doi: 10.1007/978-1-4020-2854-0_2

Schmid F (1956) La sous-famille des Drusinae (Trichoptera, Limnophilidae). Mémoires de l'Institut Royal des Sciences Naturelles de Belgique, 2. serie, 55: 1-92.

Schmidt-Kloiber A, Hering D (Eds) (2012) www.freshwaterecology.info - the taxa and autecology database for freshwater organisms, version 5.0 [accessed on 23.04.2015]

Schwarz U (2012) Balkan Rivers - The Blue Heart of Europe. Hydromorphological Status and Dam Projects. Report. Vienna, Austria, 151 pp.

Snodgrass RE (1935) Principles of Insect Morphology. Cornell University Press, Ithaca, New York, 667 pp. 
Stevanović V, Vukojičić S, Šinžar-Sekulić J, Lazarević M, Tomović G, Tan K (2009) Distribution and diversity of Arctic-Alpine species in the Balkans. Plant Systematics and Evolution 283: 219-235. doi: 10.1007/s00606-009-0230-4

Thomson RE, Holzenthal RW (2010) New Neotropical species of the genus Austrotinodes Schmid (Trichoptera: Ecnomidae). Zootaxa 2437: 38-50.

Tierno de Figueroa JM, López-Ródriguez MJ, Lorenz A, Graf W, Schmidt-Kloiber A, Hering D (2010) Vulnerable taxa of European Plecoptera (Insecta) in the context of climate change. Biodiversity and Conservation 19(5): 1269-1277. doi: 10.1007/s10531-0099753-9

Tzedakis PC (2004) The Balkans as prime glacial refugial territory of European temperate trees. In: Griffiths HI, Kryštufek B, Reed J (Eds) Balkan Biodiversity. Kluwer Academic Publishers, Dordrecht, 49-68. doi: 10.1007/978-1-4020-2854-0_4

Tzedakis PC (2009) Museums and cradles of Mediterranean biodiversity. Journal of Biogeography 36: 1033-1034. doi: 10.1111/j.1365-2699.2009.02123.x

Ursenbacher S, Schweiger S, Tomović L, Crnobrnja-Isailović J, Fumigalli L, Mayer W (2008) Molecular phylogeography of the nose-horned viper (Vipera ammodytes, Linnaeus (1758)): Evidence for high genetic diversity and multiple refugia in the Balkan Peninsula. Molecular Phlyogenetics and Evolution 46: 1116-1128. doi: 10.1016/j.ympev.2007.11.002

Vitecek S, Graf W, Previšić A, Kučinić M, Oláh J, Bálint M, Keresztes L, Pauls S, Waringer $\mathrm{J}$ (in press) A hairy case: The evolution of filtering carnivorous Drusinae (Limnephilidae, Trichoptera). Molecular Phylogenetics and Evolution.

Vitecek S, Previšić A, Kučinić M, Bálint M, Keresztes L, Waringer J, Pauls S, Malicky H, Graf W (2015) Description of a new species of Wormaldia from Sardinia and a new Drusus species from the Western Balkans (Trichoptera, Philopotamidae, Limnephilidae). ZooKeys 496: 85-103. doi: 10.3897/zookeys.496.9169

Waringer J, Graf W (2011) Atlas of Central European Trichoptera Larvae. Erik Mauch Verlag, Dinkelscherben, 468 pp.

Weiss M, Macher JN, Seefeldt MA, Leese F (2014) Molecular evidence for further overlooked species within the Gammarus fossarum complex (Crustacea: Amphipoda). Hydrobiologia 721: 165-184. doi: 10.1007/s10750-013-1658-7

Wiggins GB (1998) Larvae of the North American Caddisfly Genera (Trichoptera), second edition. University of Toronto Press, Toronto, 457 pp.

Wilke T, Schultheiß R, Albrecht C, Bornmann N, Trajanovski S, Kevrekidis T (2010) Native Dreissena freshwater mussels in the Balkans: in and out of ancient lakes. Biogeosciences 7: 3051-3065. doi: 10.5194/bg-7-3051-2010

Zakšek V, Sket B, Gottstein S, Franjević D, Trontelj P (2009) The limits of cryptic diversity in groundwater: phylogeography of the cave shrimp Troglocaris anophtalmus (Crustacea: Decapoda: Atyidae). Freshwater Biology 18: 931-946.

Zarfl C, Lumsdon AE, Berlekamp J, Tydecks L, Tockner K (2014) A global boom in hydropower dam construction. Aquatic Sciences 77(1): 161-170. doi: 10.1007/s00027-014-0377-0

Zogaris S, Economoi AN, Dimopoulos P (2009) Ecoregions in the Southern Balkans: Should their boundaries be revised? Environmental Management 43(4): 682-697. doi: 10.1007/ s00267-008-9243-y 